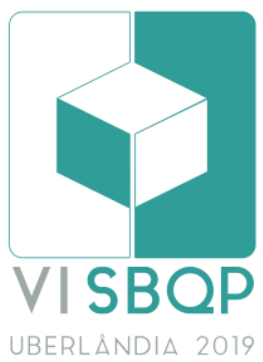

\title{
PRINCÍPIOS DE URBANIDADE NO PROJETO DE CIDADES SUSTENTÁVEIS PARA PESSOAS
}

\author{
SEABRA, Gabriela Seabra \\ UFU-Universidade Federal de Uberlândia, e-mail: gabrielaseabra.arq@gmail.com \\ DAMIS VITAL, Giovanna Teixeira \\ UFU-Universidade Federal de Uberlândia, e-mail: giovannadamis@ufu.br
}

\begin{abstract}
RESUMO
O presente artigo visa apresentar uma síntese da discussão teórica, parte da pesquisa de mestrado em Arquitetura e Urbanismo em desenvolvimento no curso de Pós-Graduação em Arquitetura Urbanismo e Design - PPGAU, na Universidade Federal de Uberlândia - UFU. A pesquisa explora o conceito de urbanidade (VITAL, 2012; AGUIAR et. NETTO, 2012; GRINOVER, 2006) aplicado a projetos urbanos de sistema viário como alternativa aos problemas causados peloplanejamento urbano, que prioriza a engenharia de tráfego, e, além disso, visa indicar eixos norteadores de projeto urbano priorizando as pessoas. O planejamento de cidades que deixa de lado a escala humana em função do automóvel particular gera cidades anônimas, inseguras e sem vida. Para identificar os elementos chave que estruturam a vida urbana é adotada a metodologia de análise do Diagrama Unidade Complexa - DUC - (VITAL, 2012). Nesse sentido e por meio das leituras das dimensões do ambiente construído e ambiental, ancoradas pelas dimensões filosófica e ecológica, será possível obter o panorama ambiental urbano de um corredor estrutural de transporte público do Setor Leste, da cidade de Uberlândia-MG. A partir do conceito de 'projeto sustentável para a cidade' (VITAL, 2012), os princípios de urbanidade serão aplicados na área de estudo visando resgatar o sentido de se projetar cidades para as pessoas.
\end{abstract}

Palavras-chave: Projeto Sustentável, Urbanidade, Cidades para Pessoas.

\begin{abstract}
The present article aims to present a synthesis of the theoretical discussion, part of the master 's research in Architecture and Urbanism under development in the postgraduate course in Architecture Urbanism and Design - PPGAU, at the Federal University of Uberlândia - UFU. The research explores the concept of urbanity (VITAL, 2012; AGUIAR et. NETTO, 2012; GRINOVER, 2006) applied to urban road system projects as an alternative to the problems caused by urban planning, which prioritizes traffic engineering, aims to indicate guiding axes of urban design giving priority to people. The city planning that leaves the human scale aside due to the private car generates anonymous, unsafe and lifeless cities. To identify the key elements that structure urban life is adopted the methodology of analysis of Complex Unit Diagram - DUC - (VITAL, 2012). In this sense and through the readings of the dimensions of the built and environmental environment, anchored by the philosophical and ecological dimensions, it will be possible to obtain the urban environmental panorama of a structural corridor of public transport of the Eastern Sector of the city of Uberlândia-MG. From the concept of 'sustainable project for the city' (VITAL, 2012), the principles of urbanity will be applied in the area of study aiming to rescue the sense of designing cities for the people.
\end{abstract}

Keywords: Sustainable Design, Urbanity, Cities for People.

SEABRA, G. S.; DAMIS VITAL, G. T. Princípios de urbanidade no projeto de Cidades Sustentáveis para pessoas. In: SIMPÓSIO BRASILEIRO DE QUALIDADE DO PROJETO NO AMBIENTE CONSTRUÍDO, 6., 2019, Uberlândia. Anais... Uberlândia: PPGAU/FAUeD/UFU, 2019. p. 1646-1656. DOI https://doi.org/10.14393/sbqp19149. 


\section{URBANIDADE}

As cidades do século XXI são reflexo do modo racional de pensar a cidade. $O$ projeto urbano da escala local é praticamente resultado da reprodução do projeto pensado para a escala global em que a engenharia de tráfego urbano determina a estruturação da cidade. Modelo baseado na priorização e facilitação dos fluxos de automóveis motorizados, individual e coletivo, em detrimento das modalidades alternativas - caminhar a pé e ciclismo.

O resultado desse pensamento racionalista do planejamento viário gera problemas ligados a qualidade ambiental urbana, como, por exemplo, a perda de canteiros centrais arborizados pelos corredores de ônibus gera impacto negativo para o conforto ambiental e para a qualidade da paisagem urbana; o impedimento de circulação e travessias dos pedestres, entre as áreas do entorno onde são inseridas, leva ao impedimento de acesso ao comércio local; a transferência do fluxo de veículos para vias localizadas no entorno imediato incrementa o baixo grau de sociabilidade entre vizinhanças; a retirada das faixas de estacionamento ao longo das vias acarreta na diminuição de público para o comércio levando a uma baixa atratividade; dentre outros.

Aliado a isso, outros aspectos contribuem para a baixa qualidade ambiental urbana em áreas projetadas a partir de tal pensamento. Em geral, a cidade torna-se artificial, desconexa da natureza, com espaços onde o sentido de identidade é frágil, o grau de legibilidade enfraquecido. Visando resolver tal problemática, Vital (2012) coloca que urbanidade é "um termo utilizado na área de arquitetura e urbanismo para definir e qualificar a dinâmica urbana, do ponto de vista social, em que experiências diversificadas são capazes de incitar e promover a presença do outro". Ela destaca que o conceito nasce da verificação crítica de Jacobs (2011) sobre a baixa qualidade ambiental urbana gerada pelo modelo de cidades modernas e propõe como parte do eixo norteador Teia Urbana, para o projeto sustentável para a cidade, o "fortalecimento da dinâmica urbana por meio da multiplicidade de usos, de informações, velocidades de fatos, fluxos de trocas, comunicação e encontros espontâneos e casuais; inclusão e equilíbrio social".

No livro 'Urbanidades' (AGUIAR et. NETTO, 2012) o tema é discutido a partir de algumas abordagens, das quais se destacam as relações entre o social e o espacial, espaço gerador da copresença; a relação entre o público urbano e os fabricantes da cidade; como a configuração espacial impacta em socialidades e comportamentos; o tempo como agente transformador de valores sociais em uma urbanidade historicamente produzida. Já para Holanda (2003:16), o conceito de urbanidade é entendido como uma condição "simultânea ao espaço físico e a comportamentos humanos". Para o presente trabalho, o estudo da urbanidade é entendido como aquele que promove e garante a interação das pessoas entre si e com o ambiente urbano.

Diante esse cenário de transformação do modo de se pensar o projeto urbano, levando em consideração a relação das pessoas com o espaço, o conceito de cidade complexa surge durante a terceira revolução urbana moderna (ASCHER, 2010). O projeto urbano passa a ser elaborado de forma complexa e se fundamenta na articulação e coordenação de potenciais variados assegurando a eficiência do conjunto de sistemas urbanos. A 
eficiência só é possível através da conexão das diversas redes, que compõe o sistema urbano, sendo este o desafio chave das dinâmicas urbanas. (ASCHER, 2010).

No presente estudo, entende-se que o transporte público é um importante agente na captação de pessoas em movimento pelas cidades, responsável por conectar um conjunto de redes urbanas, gerar e garantir o alto grau de urbanidade de um lugar. O baixo custo da tarifa, conforto de transporte, acessibilidade universal, agilidade no deslocamento, conexão com a cidade, dentre outros, configuram um transporte público de qualidade. Num cenário de mobilidade eficiente, as pessoas, geralmente, optam por deixar seus carros na garagem e adotar meios alternativos de transporte.

\section{A COMPLEXIDADE DA CIDADE COMTEMPORÂNEA}

A racionalização do desenho urbano prevê o domínio da natureza pelo homem e medidas como abertura de grandes vias para a circulação de pessoas; padronização dos edifícios otimizando o tempo de construção; extrema setorização dos usos (monofuncionalidade) na expectativa de reorganizar a cidade; e a inserção de grandes áreas verdes nos centros urbanos. Esses princípios fazem parte do conceito higienista e moderno para reordenar a cidade, promover a purificação do ar contaminado por doenças infectológicas e controle térmico.

Estes problemas, além de causarem prejuízos ambientais, com a exploração dos recursos naturais, afetam a qualidade de vida da população. As necessidades básicas de lazer e socialização do ser humano se perdem em meio à escala dos edifícios das cidades. No livro Morte e Vida de Grandes Cidades, Jane Jacobs faz uma crítica ao modelo racionalista, o qual ela denomina de 'urbanista ortodoxo' onde a rua é um lugar ruim para as pessoas. O 'balé das calçadas' é o que Jacobs (2011) afirma ser a base que sustenta a vida das cidades. O uso ativo das calçadas é o que garante a segurança e o contato entre as pessoas assim como a diversidade de usos do solo. A autora ainda revela que o que faz a cidade ter sentido e até mesmo vida são as pessoas que vivem nela.

Os espaços públicos urbanos estão cada vez mais abandonados pelas pessoas como locais de socialização e lazer, e, por mais que existam pessoas pelas ruas, seu comportamento é de isolamento, medo e insegurança. É o modelo racionalista gerando problemáticas urbanas, de paisagens frágeis quanto à conectividade, imaginabilidade, legibilidade e visibilidade. Pensar a sustentabilidade urbana, ao se projetar a cidade, ou seja, tendo como premissa o equilíbrio ambiental como garantia de gerações futuras. VitaL(2012)visa responder tais problemas. Com o avanço técnico e científico as relações de comunicação foram aprimoradas resultando na troca de informações instantânea entre sociedades. A velocidade é um dos fatores mais preciosos neste "novo tempo", se tornando característica marcante na vida urbana moderna (VITAL, 2012). Em virtude dessa velocidade e dos avanços técnicos e científicos superados a todo instante, a cidade vive em constante transformação.

A estrutura social e as relações comerciais na cidade se tronam mais complexas e necessitam de conexão, consequentemente a organização do espaço público segue este modelo de estrutura chegando ao modelo de 
Cidade Contemporânea Complexa. Nasce o entendimento de que as cidades são formadas por diversas redes estruturadas pelo pensamento sistêmico de que uma parte depende da outra, de forma que assim por diante, até configurar o todo maior (VITAL, 2012). A teia urbana que sustenta toda essa complexidade de conexões é estruturada, de acordo com Salingaros (1998), por três princípios: os nós, que ancoram teia urbana por nós de atividades humanas; conexão, formada através de pares entre nós complementares; e hierarquia, onde a teia urbana se auto organiza criando uma hierarquia ordenada de conexões em vários diferentes níveis da escala. O processo de organização segue uma ordem precisa: começando pela menor escala (caminhos de pedestres) e progredindo para escalas maiores (vias de maior capacidade) (SALINGAROS, 1998).

Em meio à diversidade de usos dentro da cidade os nós devem atrair as pessoas por alguma razão, uma atividade bem definida onde as conexões visuais são importantes para criar uma paisagem urbana coerente. Salingaros (1998) enfatiza que deve haver um equilíbrio na criação de nos semelhantes e complementares, cidades disfuncionais concentram nós do mesmo tipo, enquanto cidades funcionais concentram pares associados de nós contrastantes. Estes elementos são responsáveis por garantir a dinâmica que sustenta a vitalidade das cidades. Sua importância é ressaltada quando Ascher, 2010 reflete que:

\begin{abstract}
A terceira revolução urbana não gera, portanto, uma cidade virtual, imóvel e introvertida, mas sim uma cidade que se move e se telecomunica, constituída de novas decisões de deslocamento das pessoas, bens e informações, animada pelos eventos que exigem a copresença, e na qual a qualidade dos lugares mobilizará todos os sentidos, inclusive 0 toque, o gosto, o cheiro. (ASCHER, 2010 P. 67)
\end{abstract}

Outro fator responsável pela fragmentação da escala humana no planejamento urbano: o automóvel. Este meio de locomoção revoluciona as condições de mobilidade de pessoas e mercadorias, permitindo o deslocamento entre pontos distantes em um menor tempo. Permite que a expansão das cidades fosse possível para além do centro, e se tornou símbolo de status para as famílias. Em contrapartida, a crescente frota de veículos lota o espaço da cidade, os congestionamentos são cada vez mais frequentes em grandes cidades e os índices de polvição, pela emissão de gases no ar, aumentaram trazendo prejuízos á saúde pública.

Além da mudança morfológica e ecológica, as relações sociais na cidade contemporânea são remodeladas frentes aos avanços tecnológicos de informação. Com o surgimento da internet a comunicação acontece instantaneamente em vários lugares ao mesmo tempo, influenciando diretamente na forma como as pessoas se apropriam do espaço físico. O local já não é o lugar obrigatório da maioria das práticas sociais nos diversos campos do trabalho, da família, do lazer, da política, da religião, dentre outros (ASCHER, 2010). Torna-se cada vez mais possível escolher individualmente lugares e ocasiões de comunicação e troca. 


\section{CIDADES DOS MONUMENTOS OU DAS PESSOAS?}

O planejamento urbano modernista do início do século XX concentrou-se prioritariamente no aspecto físico das cidades, em vez do social (LYNCH, 1981). Fascinados por novas tecnologias que poderiam ser aplicadas na construção de arranha-céus e infraestrutura de sistema viário urbano, foram construídas cidades de monumentos. Estes avanços técnicos construtivos permitiram que a cidade crescesse em território e população agravando alguns problemas, como, por exemplo, perda da qualidade da paisagem urbana, alterações climáticas, rompimento dos vínculos antropossociais, baixo conforto ambiental urbano, dentre outros (VITAL, 2012).

O conceito de Urbanidade surge como resposta para reverter esse quadro de ruptura das funções sociais do espaço público. Urbanidade é um termo amplo e caracterizado essencialmente como qualidade do urbano, espaço gerador da copresença, ou referente a tudo que se diz respeito á vitalidade urbana (AGUIAR et. NETTO, 2012). O termo Urbanidade é conceituado de modo geral no dicionário Aurélio como caráter do urbano, onde urbano é tudo que envolve e constrói a cidade, e caráter como qualidade que distingue um e outro. Sendo assim, temos a definição de urbanidade ainda como à qualidade da cidade, qualidades estas boas ou ruins que moldam a cidade.(VITAL,2012) Este conceito é um tanto quanto genérico ao considerarmos as infinitas possibilidades e aspectos que formam e transformam a cidade, e por isso é relevante aprofundar sua abordagem diante os aspectos fenomenológicos antropossociais e políticos, onde a Urbanidade é definida como parâmetro maior, e abrangente, na avaliação da qualidade urbana dos lugares (AGUIAR, 2012).

Aguiar (2012) define urbanidade como qualidade dos espaços da cidade que acolhem as pessoas, onde espaços com urbanidade são espaços hospitaleiros. O que torna a cidade bonita e hospitaleira, segundo Grinover (2006), é sua capacidade de expressar um microcosmo social e arquitetônico ordenado, no qual cada edifício, por sua dimensão, por seu refinamento e seu esplendor, mostra não só sua própria importância, mas também a importância de quem o encomendou, e que ali vive. Assim, o diagnóstico de um alto grau de urbanidade, qualifica a cidade a uma condição de acolhimento, que recebe as pessoas com civilidade, polidez e cortesia (AGUIAR, 2012).

Vale ainda destacar, de acordo com Aguiar (2012), que essa condição de hospitalidade do lugar é associada às condições físicas e materiais do ambiente construído, ou seja, a qualidade dos elementos que compõe o espaço, vinculada á dinâmica das experiências vivenciadas pelas pessoas que fazem uso do ambiente público urbano. "Algo essencialmente da forma, da forma urbana, algo típico e único do ambiente construído" (CASTELO, 2007 apud. AGUIAR, 2012). Ao tratar de como as pessoas sentem esse espaço físico hospitaleiro ou não Grinover (2006) afirma que o viajante, o turista, o migrante, quando chega a uma cidade e percorre os espaços que constroem essa forma urbana, é submetido a um sem-número de percepções, de situações e de processos importantes de informações. São impostos por elementos tangíveis e intangíveis, que o envolvem e o induzem a comportamentos hospitaleiros, ou não.

Hospitalidade é uma qualidade social antes de ser uma qualidade individual: é um fenômeno que implica uma organização, um ordenamento de lugares coletivos e, 
portanto, a observação das regras de uso desses lugares. [...] A hospitalidade supõe a acolhida; é uma das leis superiores da humanidade, é uma lei universal. Acolher é permitir, sob certas condições, a inclusão do outro no próprio espaço. A hospitalidade, como diz Jacques Godbout (1997), é um dom do espaço; espaço a ser lido, habitado, atravessado ou contemplado. (GRINOVER, 2006, P. 31-32)

Complementando o conceito de Urbanidade, como espaços de hospitalidade urbana, Netto (2012) ainda explora três dimensões que sustentam a urbanidade, são elas, a dimensão fenomenológica com o reconhecimento do outro a partir da sua presença; a dimensão comunicativa da cidade e seus espaços como loci do convívio urbano; e a dimensão ontológica que consiste na relação entre práticas e espaços da cidade como dados estruturantes da realidade material. Netto (2012) explica que a dimensão fenomenológica da urbanidade introduz a possibilidade de vivenciar experiências em comum, estreitando a relação entre sujeito e mundo, atribuindo o papel do espaço urbano na determinação de como "eu apreendo o outro". Essa relação de copresença é alcançada através da dimensão comunicativa da urbanidade, onde a cidade é o local de maior interação entre as pessoas, onde elas se comunicam. A ligação entre o humano e o material é reconhecida na dimensão ontológica da urbanidade, sendo definida por Netto (2012) como as possibilidades gerais do ser, aquilo que torna possível múltiplas existências. O espaço urbano assume o papel de meio integrador da realidade social e material conectando diferentes agentes sociais e temporais. A intensificação dessa integração das trocas urbanas e dinâmicas cotidianas pode ser definida também como urbanidade.

Cada cidade ou espaço é carregado de uma história, cultura e pessoas que com o passar do tempo construiu e continua construir a sua identidade e urbanidade. O fator temporal é extremamente importe neste aspecto, pois a cidade comporta a expressão de várias temporalidades em seus edifícios, costumes e usos, e com isso a urbanidade não é algo que pode ser considerado estático, pois ela acompanha a evolução temporal de cada cidade com suas particularidades. Sendo assim é possível identificar urbanidades passadas, presentes e futuras.

A urbanidade, ainda, é entendida por Hillier e Hanson por meio de três pilares: a condição de rede, o desenho global e a Arquitetura (AGUIAR, 2012). A condição de Rede corresponde à organização global do espaço atuando como um meio através do qual cidade e áreas urbanas podem tornar-se potentes mecanismos capazes de gerar, sustentar e controlar os padrões de movimento de pessoas; já o desenho global sobrepõe as condições locais e globais no espaço urbano, existindo no habitante urbano a consciência do posicionamento, de localização, inerente a cada ponto da rede urbana, na sua condição de centralidade. Nesse sentido, o quão público um espaço é seria expresso na intensidade da interface entre moradores, os habitantes do lugar, e os visitantes ou, os estranhos. Urbanidade é um conceito complexo e estrutura vários elementos da dinâmica urbana, sendo um deles a vitalidade. No entanto, Aguiar (2012) reforça que urbanidade não é sinônimo de vitalidade.

As partes da cidade mais integradas espacialmente, mais oxigenadas, são aquelas com maior vitalidade, com mais pessoas utilizando, vivenciando o espaço. Por outro lado, se 
uma determinada situação urbana é sintaticamente segregada ela terá, por genética, por natureza espacial, um baixo grau de urbanidade, ainda que ela seja localmente bastante constituída. Essa mesma situação, curiosamente, poderá, no entanto ter um alto grau de vitalidade, presença de pessoas, e mesmo sucesso comercial, dependendo do grau de atratividade das atividades que ali se localizam. Ainda assim essa situação terá, por definição, um baixo grau de urbanidade; ela sempre dependerá de atratores para a realização de sua vitalidade.

(AGUIAR, p. 12, 2012)

Diagnosticado um alto grau de urbanidade, consequentemente haverá pessoas. No entanto, a condição de urbanidade é uma característica própria da cidade, da forma, e não das pessoas, sendo assim urbanidade não pode ser confundida com vitalidade, pois a urbanidade é um tipo de espacialidade, entendida como relação entre espaço e pessoas. Ou seja, o modo como à relação corpo/espaço se materializa (AGUIAR, 2012). Grinover (2006) afirma que a urbanidade não é algo que só arquiteto observa, percebe e sente. "Trata-se de algo que qualquer pessoa com um pouco mais de sensibilidade observa, percebe e sente na própria pele", o autor ainda acrescenta que a condição de informalidade dos espaços públicos, geralmente oferecem uma condição "desurbana", agressiva e hostil, sendo também facilmente percebido e sentido pela população. Grinover (2006) destaca que nem sempre a população está de acordo com o que espera da cidade, e por isso podemos esperar diferentes percepções de urbanidade da população.

\begin{abstract}
Partir da certeza de que existe uma estreita relação entre o funcionalismo arquitetônico e urbanístico (Bauhaus e "Carta de Atenas") e utilitarismo teórico, que dominou por mais de dois séculos nas ciências sociais, na filosofia política, a experiência da cidade moderna é aquela da ambivalência e, nesse sentido, Didier Lapeyrronnie (1999) exprime admiravelmente essa "ambigüidade profunda" da cidade. Desejamos, de acordo com o autor, a ligação e a ruptura, o engajamento e a liberdade, a proximidade e a distância. Ela deve carregar 0 passado e o futuro, o enraizamento e o desenraizamento, o desconhecido e o familiar, o parecido e o cosmopolita, a calma e a agitação, desejamos intensamente mudar e ficar os mesmos. Achamos nossas cidades, simultaneamente, magníficas e horrendas; amamos e detestamos nossas cidades modernas. (GRINOVER, 2006, p. 35-36)
\end{abstract}

A urbanidade é, portanto, uma condição sinérgica, uma qualidade-mãe do espaço urbano que engloba e ancora tantas outras. O conceito de urbanidade, nesta pesquisa, fundamenta a análise das condições do espaço público urbano na escala do pedestre para que o projeto de cidade garanta a qualidade ambiental urbana. Entendendo o sistema de mobilidade urbana como um elemento chave-estruturador do tecido urbano e para 0 fortalecimento do grau de urbanidade, será aplicada a metodologia DUC de Vital (2012) para a leitura do estudo de caso do Corredor Estrutural Leste de Transporte Público em Uberlândia-MG. Para essa autora, os conceitos de 'urbanidade, identidade e acessibilidade e habitabilidade' estão interconectados entre si e enquadram-se como um dos eixos norteadores para o desenvolvimento do "Projeto Sustentável para a Cidade". 
No sentido desse conceito, somos conduzidos olhar para a cidade sob ponto de vista ecológico, sistêmico e complexo em que a urbanidade configura a qualidade necessária para o desempenho do alto grau de 'qualidade ambiental urbana'. Condição capaz de promover o desenvolvimento da sociedade por meio do fortalecimento dos vínculos antropossocias e do bemestar das pessoas.

\section{O PANORAMA AMBIENTAL URBANO}

Os elementos chaves estratégicos, que podem estruturar a vitalidade urbana e, consequentemente, um alto grau de urbanidade, estão inseridos nas premissas do conceito de 'Projeto Sustentável para a Cidade' (VITAL, 2012), na Dimensão do Ambiente Construído e suas categorias de Desenho Universal Urbano e Espacialização de Elementos - Chaves Estruturantes, e na Dimensão da Teia Urbana com suas categorias de Dinâmica Urbana: Fluxos e conexões e Estratégia chave: Elementos Chaves Estratégicos. Para construir o Panorama Ambiental Urbano, é adotada a metodologia de análise do Diagrama de Unidade Complexa - DUC -, estruturada em quatro dimensões instrumentalizadas em categorias de análise e de projeto. Todas fundamentadas, primordialmente, em abordagens de fenomenologia sistêmica e hierarquia sistêmica.

Na Dimensão do Ambiente Construído é avaliado se o espaço público apresenta potencial de promover, ou não, a vida social como espelho da sociedade e suas relações. A partir daí, são identificadas as conexões existentes entre a tecitura urbana e os links ecológicos e é realizada a avaliação da morfologia urbana por meio da análise da geometria da forma da cidade verificando o grau de facilidade de interações humanas. Nesta dimensão, para este trabalho, tem-se o desenvolvimento da camada (layer) vermelha com o objetivo de identificar como o traçado e a legibilidade urbana repercutem no dia a dia dos usuários. Vital (2012) caracteriza essa análise como subsídio ao "dimensionamento do grau de dinâmica urbana, dos sentidos de liberdade pessoal dos cidadãos e de interatividade, característicos da condição de urbanidade".

A Dimensão da Teia Urbana busca entender como a vida urbana se organiza, e em quais áreas o sentido de urbanidade é maior. Nessa dimensão, para este trabalho, tem-se o desenvolvimento da camada violeta envolvendo os mecanismos subjetivos e imateriais (Intangíveis) e os mecanismos objetivos e materiais (tangíveis). A partir da observação de como se dá todos os fluxos na configuração dos espaços públicos, encontra-se o grau de dinamismo urbano, o sentido de urbanidade e de identidade cultural.

Vale destacar que a legibilidade é entendida aqui como um importante indicativo para a estruturação do grau de urbanidade de determinado local, uma vez que é compreendida como a qualidade visual de uma cidade, de um território, examinada por meio de estudos da imagem mental que dela fazem, antes de qualquer outro, os seus habitantes (GRINOVER,2006). Com legibilidade pretende-se indicar a facilidade com que as partes de uma cidade podem ser reconhecidas e organizadas num modelo coerente.

Plena conectividade, oferta de espaços públicos propícios para as atividades de lazer, recreação e ócio, a ambiência adequada às manifestações culturais e sociais, e aos encontros 
casuais, conexão ecossistêmica, o conforto ambiental, a agradabilidade visual, a legibilidade fortalecem o sentido de pertinência e identidade social e cultural, e compõem 0 sentido de urbanidade. (VITAL, 2012, p. 259)

O principio de conectividade é outro aspecto que deve ser ressaltado, pois quanto maior a possibilidade de conexões menores são as possibilidades de travamentos de fluxos (VITAL,2012). Desta forma a conectividade entre moradia, trabalho e lazer tornam-se mais eficaz e sustentável. Outra característica da condição de urbanidade está relacionada com 0 dimensionamento do grau de dinâmica urbana, dos sentidos de liberdade pessoal dos cidadãos e interatividade. (VITAL, 2012).

Os nós que sustentam a dinâmica da teia urbana promovem e articulam a socialização das pessoas. Na sociedade complexa alguns desses nós acontecem no ambiente virtual, porém ainda existe a necessidade do contato físico proporcionado pelos encontros nos espaços públicos. Tendo como princípio de que a vitalidade urbana é ancorada pela socialização das pessoas e que o movimento de deslocamento entre os nós acontece através dos meios de transporte, o sistema viário se faz um dos elementos base do desenvolvimento das cidades.

A cidade contemporânea complexa é regida pelo princípio do pensamento sistêmico, onde quanto maior o número de conexões dos nós mais prospera e organizada ela é. Ao estudar o sistema viário urbano é perceptível que a dinâmica da cidade acompanha a hierarquia viária, onde eixos de vias estruturais abrigam os principais nós de atratividade humana, diluindo-se com o restante das vias. Sendo assim qualquer modificação em determinado ponto do sistema viário implica em uma reconfiguração da dinâmica urbana local, visto que a rede se configura em um todo maior e exerce influência ele. Diante deste fato, fica a importância de inserir os princípios de urbanidade em projetos de requalificação de sistema viário urbano.

Em complemento ao estudo das camadas (layers) vermelho e violeta, a metodologia DUC compreende outras dimensões, que fazem parte de um todo maior, e, por isso, é necessário agregar a pesquisa a interpolação das camadas (layers) azul, que analisa o elemento água e sua influência na vida urbana com práticas de projeto sustentável a partir deste elemento, a verde, que contempla o papel da vegetação nos espaços livres na cidade como conforto climático, filtro do ar poluído e refúgio para os animais; a marrom, para compreensão do solo e relevo; e a cinza, com o estudo do clima. É importante destacar a necessidade do das demais leituras, pois, por meio de sua interpolação obtém-se a síntese de todas as categorias evidenciando os pontos cruciais e fundamentais ao desenvolvimento do conceito de 'Projeto Sustentável para a Cidade'. Além de reconhecer as conexões, torna-se de fundamental importância reconhecer a qualidade dessas conexões em que as positivas promovem equilíbrio ecossistêmico e as negativas geram impacto e degradação ambiental. Assim, uma conexão entre os elementos é rompida, prejudicada ou eliminada do contexto sistêmico, perde-se a ordem e o equilíbrio natural desestabiliza-se. 


\section{CONCLUSÕES OU CONSIDERAÇÕES FINAIS}

Por muito tempo a condição humana é esquecida no planejamento da cidade moderna. Os avanços tecnológicos e de comunicação tem mudado o comportamento das pessoas e como elas se apropriam do espaço. Este trabalho destaca a necessidade de resgatar o foco e a atenção para a escala humana nos projetos na escala urbana, para os espaços públicos e, especialmente, para o sistema viário.

Para isso, entende-se que explorar a dimensão conceitual sobre Urbanidade significa estabelecer a base fundamental para se entender como projetar espaços urbanos, ou seja, espaços que sejam hospitaleiros e geradores de copresença nas cidades. Assim, a partir dessa compreensão, identificar os elementos chaves estruturadores da dinâmica urbana por meio da leitura da paisagem urbana. Esclarecemos que a leitura e análise dos layers, utilizando o Diagrama de Unidade Complexa, utilizado para elaborar o panorama ambiental urbano da avenida estrutural Segismundo Pereira no Setor Leste da cidade de Uberlândia-MG será realizada em momento futuro da pesquisa.

Através do embasamento teórico fica claro que o espaço físico da cidade é capaz de atrair ou repelir as pessoas que fazem uso dele, onde o sistema de mobilidade das pessoas não é uma condição exclusiva do automóvel, sendo necessário abordar alternativas de inserir outros meios de transporte tais como, a bicicleta, transporte público e a pé. A partir da necessidade de uma malha urbana mais integrada que comporte os vários tipos de mobilidade outros elementos são necessários para elevar o grau de urbanidade, como por exemplo, a arborização de praças e canteiros centrais; mobiliário urbano ergonômico; iluminação pública adequada para pedestres; diversidade de usos; calçadas acessíveis dentre outros.

Por fim, a expectativa dessa pesquisa é instrumentalizar o projeto urbano contemporâneo de cidades médias brasileiras, onde o sistema viário de transporte público seja elemento chave estruturador da dinâmica urbana. No caso da cidade de Uberlândia, a pesquisa se faz importante para compreender as diretrizes de projeto utilizadas na implantação do corredor estrutural leste e as consequências na paisagem, morfologia, economia e nos vínculos antropossociais presentes na área de implantação. A partir desse diagnostico, será possível aplicar a metodologia de análise apresentada aqui, para nortear a identificação de elementos que qualificam ou não a forma de implantação de outros corredores de ônibus previstos no planejamento de expansão do transporte público, em Uberlândia.

\section{REFERÊNCIAS}

AGUIAR, Douglas. Urbanidade e a qualidade da cidade. Arquitextos, São

Paulo, ano 12, n.141.08, Vitruvius, mar. 2012.<

http://www.vitruvius.com.br/revistas/read/arquitextos/12.141/4221>.

ASCHER, François. Os Novos Princípios do Urbanismo. São Paulo: Romário Guerra, 2010.

GAETE, Constanza Martínez. 5 conselhos de desenho urbano, por Jan Gehl . 02

Set 2016. ArchDaily Brasil. (Trad. Brant, Julia) Acessado 4 Jun 2019.

<https://www.archdaily.com.br/br/794345/5-conselhos-de-desenho-urbano-

por-jan-gehl> ISSN 0719-8906 
GEHL, Jan 1936- Cidades para Pessoas/ Jan Gehl; tradução Anita Di Marco. $2^{\circ}$ ed. São Paulo. Editora Perspectiva, 2013.

GRINOVER, LUcio. A hospitalidade urbana: acessibilidade, legibilidade e

identidade. Revista Hospitalidade, São Paulo, ano III, n. 2, p. 29-50, 2. sem. 2006.

JACOBS, Jane. Morte e Vida de grandes Cidades, $3^{\circ}$ edição. São Paulo: Editora WMF Martins Fontes, 2011.

LEFEBVRE, Henri. O Direito a Cidade. São Paulo, Ed. Centauro, 20015 Ed. Tradução: Rubens Eduardo Frias.

LYNCH, Kevin. A boa forma da cidade. Massachusetts. Edições 70,1981.

SALINGAROS, Nikos A. A Teoria da Teia Urbana. Tradução Lívia Salomão

Piccinini. Original publicado no Journal of Urban Design. Volume 3. 1998,

páginas 53-71.

SENNETT, Richard. O declínio do homem público. 1ed. Rio de janeiro:

Record,2014. Tradução de: the fall of public man.

TANSCHEIT, Paula. Dez cidades abrem ruas para devolvê-las às pessoas. 06 Mar 2017. ArchDaily Brasil. Acessado 4 Jun 2019.

<https://www.archdaily.com.br/br/806515/dez-cidades-abrem-ruas-para-

devolve-las-as-pessoas> ISSN 0719-8906

URBANIDADES. Organização Dougulas Aguiar e Vinicios M Neto. Urbanidades. Rio de Janeiro: Folio Digital: Letra e Imagem,2012.

VITAL, Giovanna Teixeira Damis. Projeto Sustentável para a Cidade: o Caso de Uberlândia. São Paulo,2012. Tese de Doutorado apresentado a FAUUSP. 